\title{
Huge Sertoli-Leydig cell tumor: a rare case report
}

\author{
Mridula Raghav*, Ashok R. Anand
}

Department of Gynecology and Obstetrics, Grant Medical College and JJ Group of Hospital, Mumbai, Maharashtra, India

Received: 24 October 2019

Revised: 21 November 2019

Accepted: 28 November 2019

\section{*Correspondence:}

Dr. Mridula Raghav,

E-mail: fabulousmridula@gmail.com

Copyright: () the author(s), publisher and licensee Medip Academy. This is an open-access article distributed under the terms of the Creative Commons Attribution Non-Commercial License, which permits unrestricted non-commercial use, distribution, and reproduction in any medium, provided the original work is properly cited.

\begin{abstract}
Sertoli-Leydig cell tumors (SLCTs), constitute less than $0.5 \%$ of all ovarian tumors. SLCT are rare after menopause (less than10\%), 75 years, unmarried, postmenopausal since 30 years, presented with complaints of abdominal swelling. On examination, abdominal mass of 36 weeks, hard, immobile felt. Ultrasonography of abdomen showed lobulated solid cystic lesion of size $22 \times 15 \times 27 \mathrm{cms}$ with bilateral ovaries not separately visualized. Moderate free fluid in the abdomen, suggestive of malignant neoplastic etiology. CECT Abdomen + pelvis suggestive of primary ovarian malignancy with omental deposits and pelvic adenopathy. CA 125- 415.1 Patient underwent total abdominal hysterectomy with bilateral salpingo-oophorectomy with huge tumour mass excision (weight $5.25 \mathrm{~kg}$ ) with umbilical hernia repair. Frozen section suggestive of a huge mass of $30 \times 20 \times 15 \mathrm{~cm}$, multilobulated, yellowish white tan in colour, solid-cystic in consistency, seen arising from right ovary. Omentum appears normal. Histopathology report s/o- Moderately differentiated Sertoli Leydig cell tumor. Reporting the first, this huge, in this age group with atypical presentation.
\end{abstract}

Keywords: Ascites, Large ovarian tumor, Postmenopausal tumor, Sertoli -Leydig cell tumors

\section{INTRODUCTION}

Ovarian sex cord-stromal tumors are uncommon neoplasms, constitute less than $0.5 \%$ of all ovarian tumors and typically present in the first two to three decades of life, with the exception of adult granulosa cell tumors, which typically present later, with risk for development peaking at age 50 to 55 years. ${ }^{1}$ In aggregate, these tumors account for approximately $5 \%$ of ovarian malignancies in women age 15 to 24 years. These tumors are unilateral, confined to the ovary, and large frequently characterized by the presence of androgen production, only $30 \%$ of patients display virilization or defeminisation on presentation. ${ }^{2}$ Sex cord-stromal tumors usually present with the typical symptoms of an adnexal mass, including abdominal pain, distention, and, rarely, torsion.

\section{CASE REPORT}

A 75 years old female, unmarried, postmenopausal since 30 years, recently diagnosed case of hypertension, presented with complaints of abdominal swelling gradually increasing in size over a period of one year. On general examination patient was moderately built, vitally stable, per abdomen distended, dilated veins present, umbilical hernia of size $5 \times 5 \mathrm{~cm}$ present, mass of 36 weeks, hard, immobile, lower limit not palpable, per speculum/per vaginum examination not done in vivo of unmarried status. On investigating further, haemoglobin was $9.5 \% \mathrm{~g}$. Ultrasonography of abdomen showed uterus $6.5 \times 10 \times 9.5 \mathrm{cms}$, appears mildly bulky, a well-defined hypoechoic lesion $4.2 \times 4.4 \mathrm{cms}$ in size in uterine body suggestive of intramural fibroid, a large well defined, lobulated solid cystic lesion of size $22 \times 15 \times 27 \mathrm{cms}$ 
noted involving whole of the abdomen extending from epigastrium to hypogastrium region, also extending into the pelvis with bilateral ovaries not separately visualized from the lesion (right > left). The solid areas show vascularity within on colour doppler. The lesion is also extending through a defect in midline in umbilical region $4 \mathrm{~cm}$ in size. Moderate free fluid in the abdomen. No significant lymphadenopathy suggestive of malignant neoplastic etiology. CECT (abdomen and pelvis) showed a large well defined, lobulated solid cystic lesion of size $17 \times 20 \times 28 \mathrm{cms}$ noted involving whole of the abdomen extending from supramesocolic peritoneum inferiorly up to the POD. Bilateral ovaries not separately visualized from the lesion (right > left) (Figure 1-6). The lesion is also extending through a defect in midline in umbilical region $4 \mathrm{~cm}$ in size. Anteriorly fat planes with the urinary bladder are indistinct, posteriorly fat planes with the rectum and uterus are lost. Diffuse omental nodularity is seen. Mild ascites is seen. Bilateral sub-centimeter sized external and internal iliac lymph nodes are seen suggestive of primary ovarian malignancy with omental deposits and pelvic adenopathy CA 125-415.1.

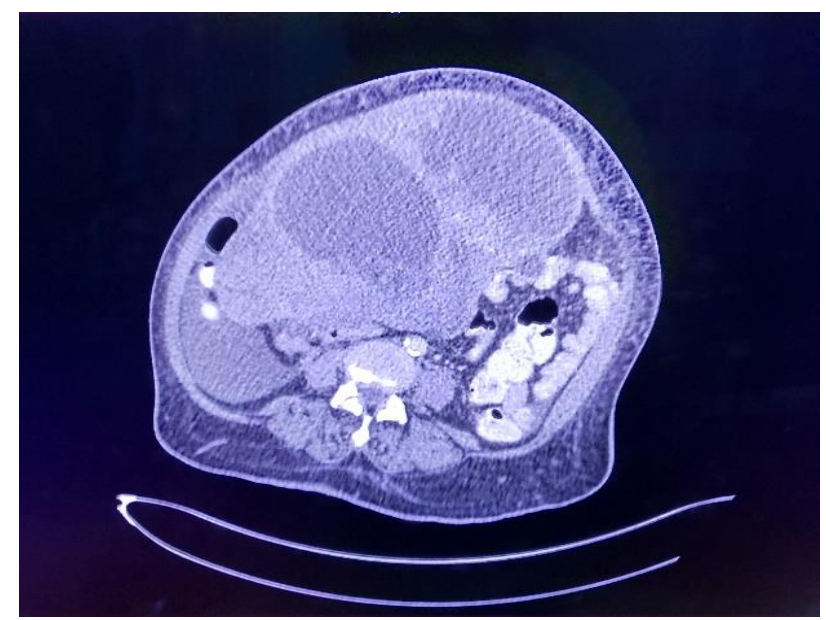

Figure 1: Axial section of abdomen of large solid cystic mass occupying whole of andomen.

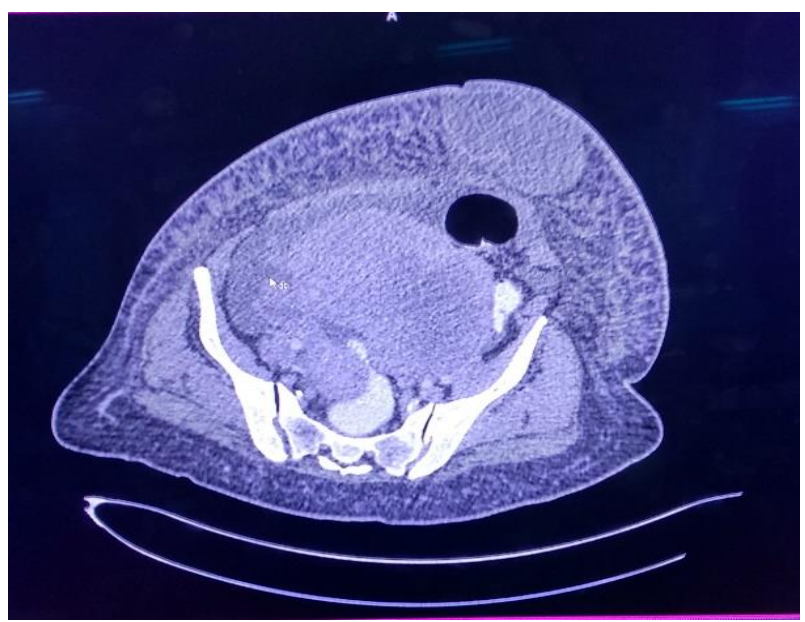

Figure 2: The lesion is also extending through a defect in midline in umbilical region $4 \mathrm{~cm}$ in size.

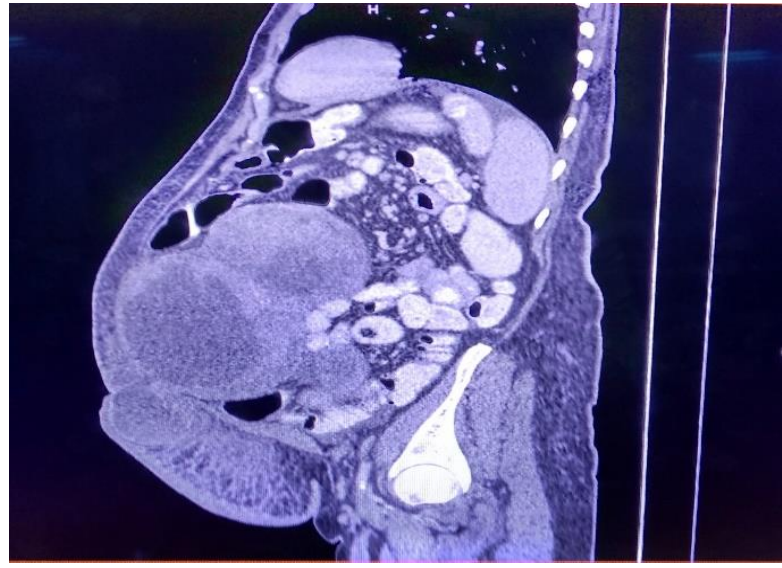

Figure 3: Sagittal section of entire tumor extending from epigastrium to hypogastrium region.

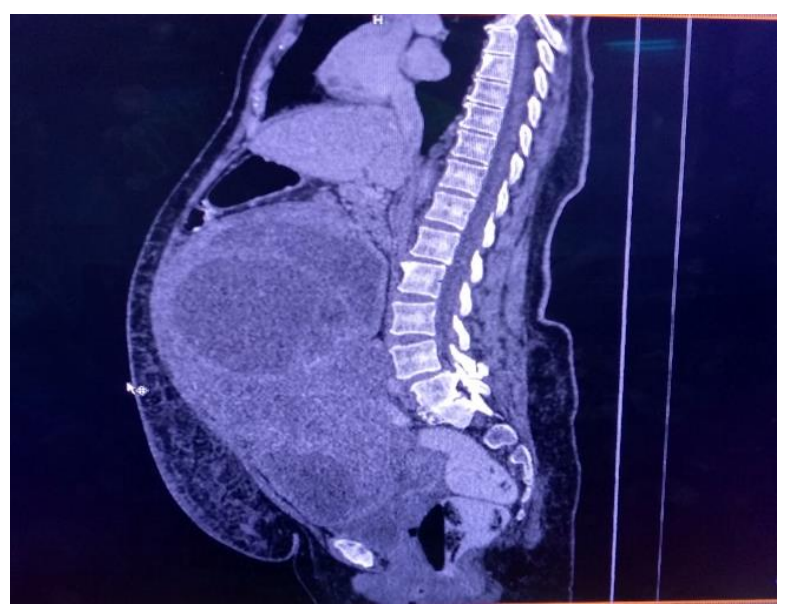

Figure 4: Solid cystic areas in the tumor with normal appearing uterus.

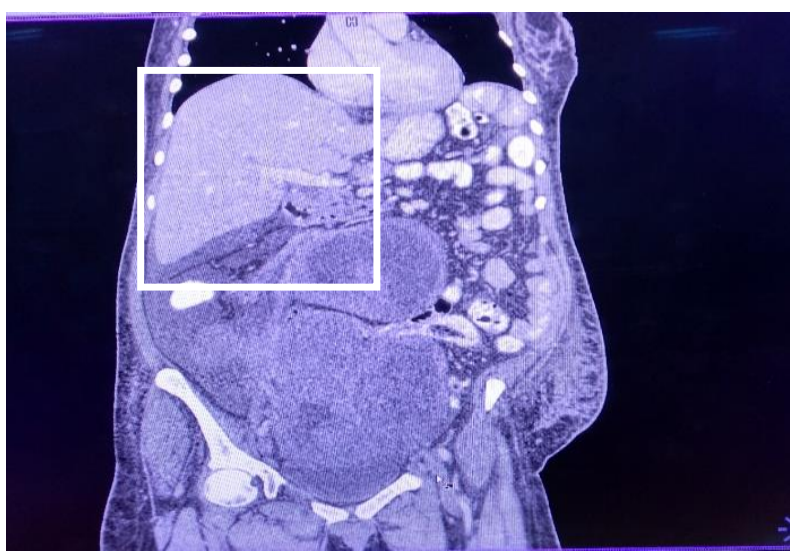

Figure 5: Coronal section of normal liver with no metastasis, free fluid present in hepatorenal pouch.

Patient was then posted for exploratory laparotomy under general and epidural anaesthesia after fitness and all high risks explained, patient underwent total abdominal hysterectomy with bilateral salpingo-oophorectomy with huge tumour mass excision (weight $5.25 \mathrm{~kg}$ ) with umbilical hernia repair. Intraoperatively uterus was 10-12 
weeks with left ovary and tube normal. A huge mass of $30 \times 20 \times 15 \mathrm{~cm}$, multilobulated, yellowish white tan in colour, solid- cystic in consistency, seen arising from right ovary with stretched out right fallopian tube (Figure 7-10). Umbilical hernia of $5 \times 5 \mathrm{~cm}$ in size. Omentum appears normal.

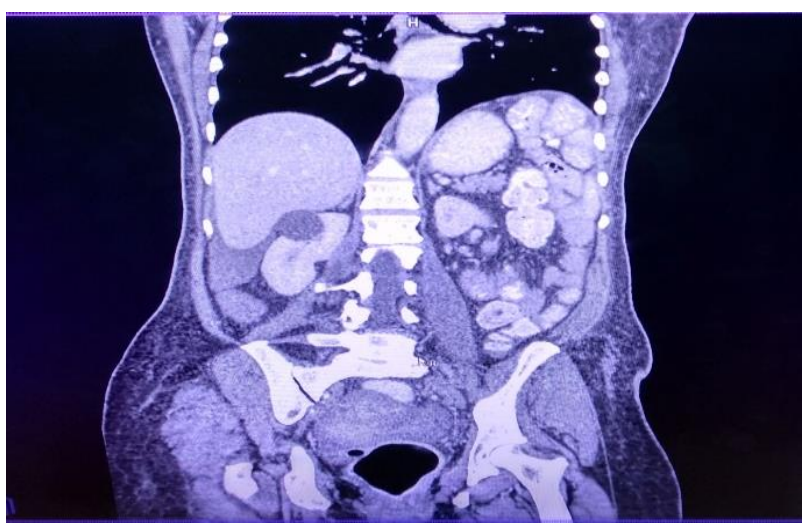

Figure 6: No evidence of any metastasis to kidneys, uterus appears normal.

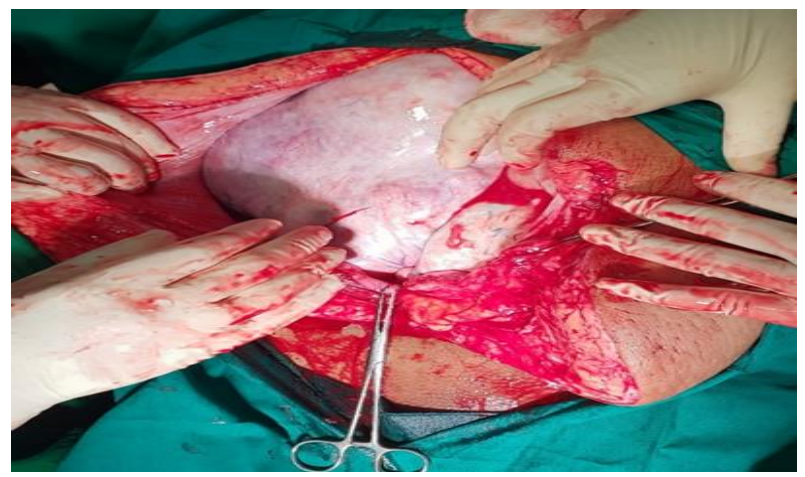

Figure 7: Yellowish white tan solid cystic mass.

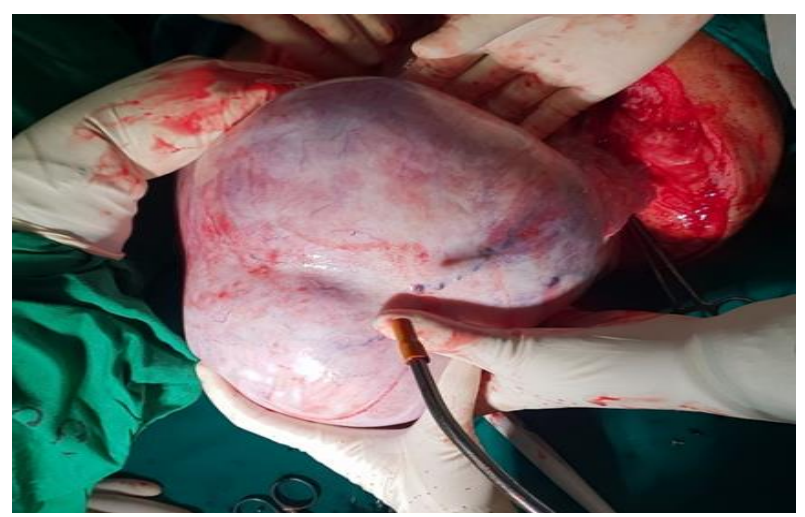

Figure 8: Intraoperative image of tumour mass approx. $30 \times 20 \times 15 \mathrm{~cm}$ in size $(5.25 \mathrm{~kg})$.

\section{Frozen section report}

Right ovarian tumour $31 \times 22 \times 15 \mathrm{~cm}$ in size, externally lobulated with stretched out right fallopian tube $21 \mathrm{~cm}$ in length, on cut sections tumour is solid and cystic with
$70 \%$ solid areas, soft to firm, yellowish tan in colour, $30 \%$ tumour is cystic, cyst wall is smooth, one cyst shows papillary projections s/o right ovarian mass - benign sex cord stromal tumour suggestive of Sertoli cell tumour.

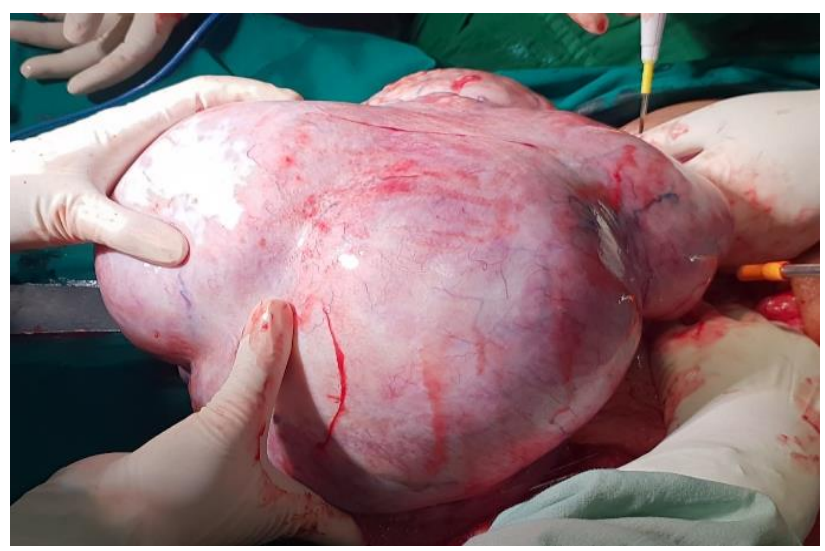

Figure 9: Right ovarian mass, multilobulated with vascular areas.

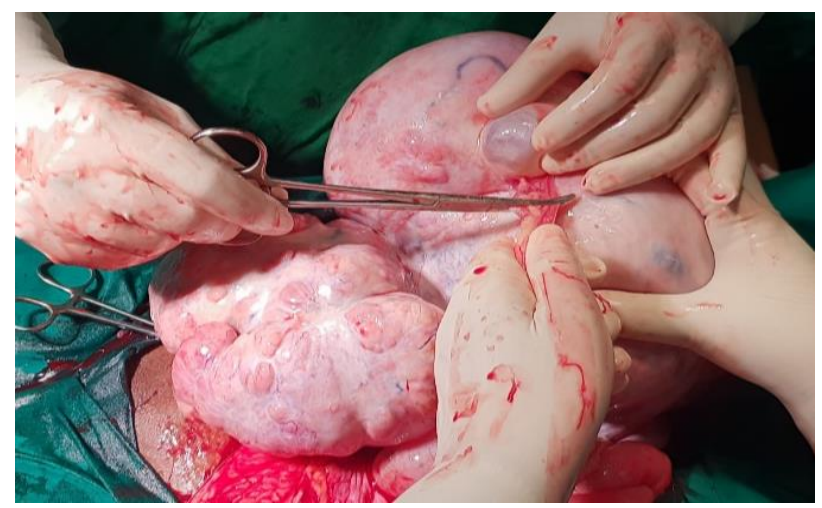

Figure 10: Multiple solid cystic areas seen with artery clamped at tumour pedicle.

\section{Final histopathology report}

Microscopic description - sections through right ovarian mass reveal tumour arranged in compact bundles and fascicles with oedematous stroma, at places lobular architecture is seen. Within the cellular area comprised of spindle cells with bland oval to elongated nuclei with eosinophilic cytoplasm. Few cysts are lined with flattened Sertoli cells. Few areas show round cells with eosinophilic, vacuolated cytoplasm with eccentrically placed nuclei, areas of hyalinization. Mitotic activity seen (Figure 11-13).

\section{Impression}

Figure 14 shows right ovarian mass - sex cord stromal tumour with differentials as-

- Moderately differentiated Sertoli Leydig cell tumour.

- Fibroma. 
Hysterectomy with left salpingo-oophorectomy specimen

- Endometrium - hyperplastic polyp

- Myometrium - intramural leiomyoma

- Cervix-chronic non - specific endocervicitis

- Left ovary- follicular cyst with corpus albicans.

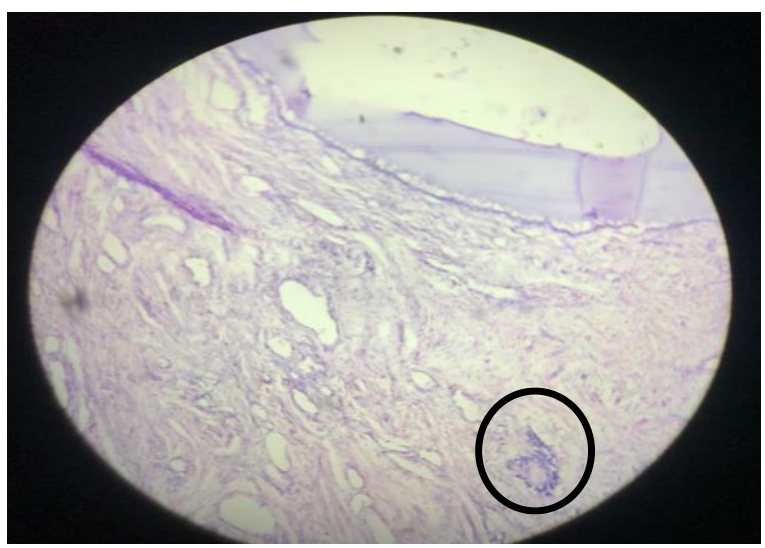

Figure 11: High power field view of tumour section showing Sertoli- Leydig cells.

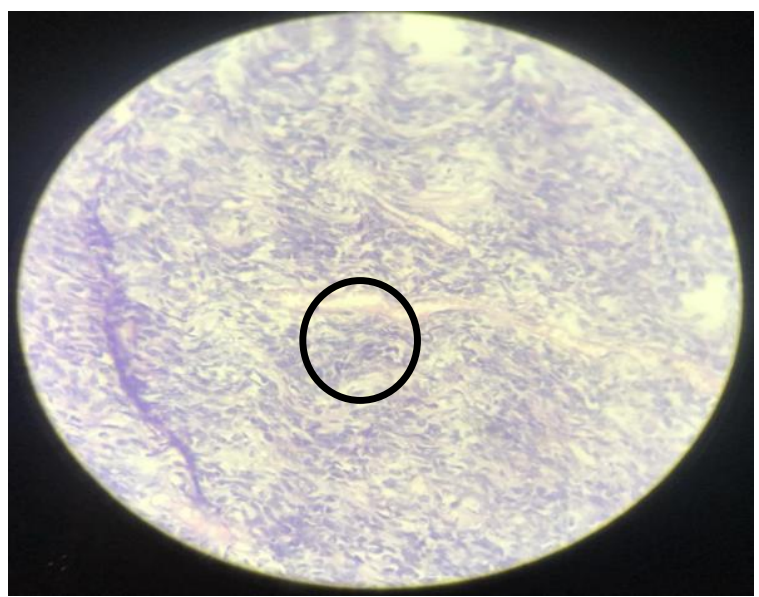

Figure 12: Encircled area shows Sertoli-Leydig cells.

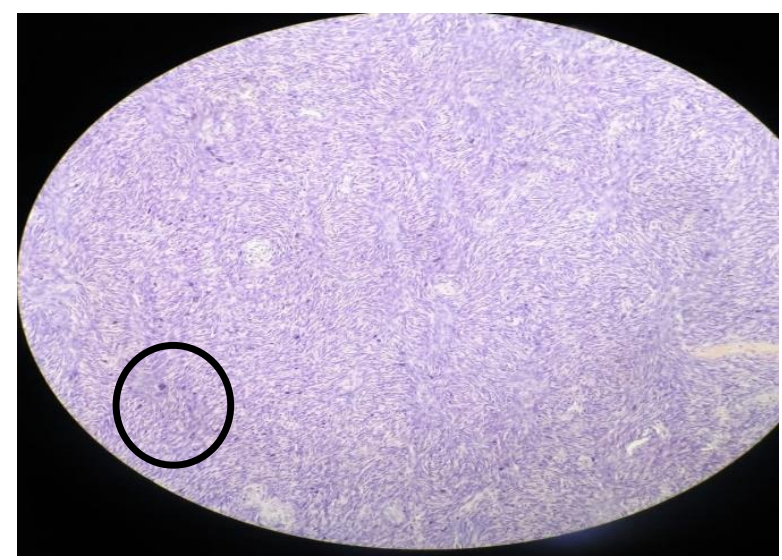

Figure 13: Low power field view of tumour section showing lobular architecture, encircled area showing Sertoli-Leydig cell.

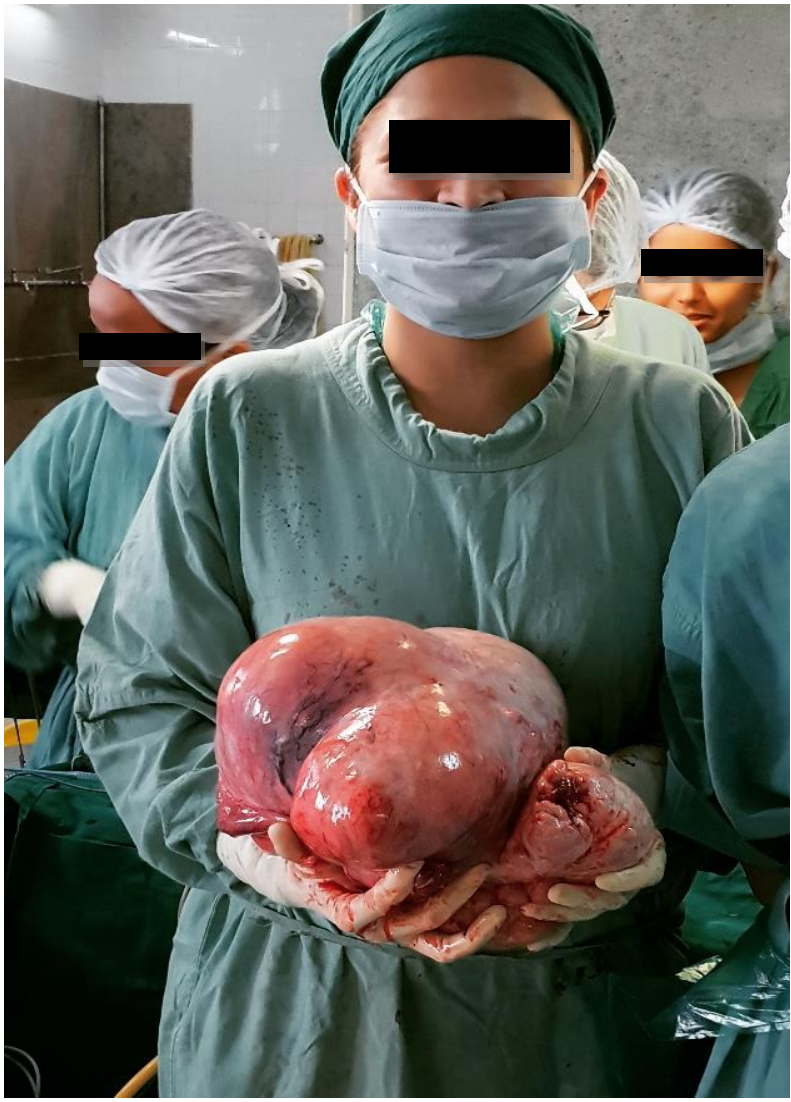

Figure 14: Right ovarian tumor after removal, the size of the tumor was $31 \times 22 \times 15 \mathrm{~cm}$ and the tumor weighed $5.25 \mathrm{kgs}$.

\section{DISCUSSION}

A case has been reported of Sertoli-Leydig cell tumor of the ovary in a postmenopausal woman, usually, the patients affected by this tumor were young women with virilization signs. Patient doesn't show any virilization or other signs which indicates the presence of this tumor. SLCTs are commonly unilateral and usually confined to the ovary at the time of diagnosis. Bilateral involvement is seen in less than $2 \%$ of the cases. Grossly, they are predominantly solid but cystic areas may be seen. Welldifferentiated SLCTs are smaller in size with a mean diameter of $5 \mathrm{~cm}$ while intermediate and poorly differentiated tumours have an average diameter of 15 $\mathrm{cm}$. Ultrasound is regarded as a useful imaging technique for the initial assessment of SLCTs. Other imaging techniques like CT, MRI, and PET scans are more useful in tumour staging.

The histologic appearance of these tumours is extremely variable and has been categorized into the following groups-

- Well differentiated - solid or hollow tubules composed of Sertoli cells surrounded by a fibrous stroma containing clusters of Leydig cells. Lacks significant atypia or mitotic activity. 
- Intermediate differentiated - large cellular 'blue nodules' surrounded by an oedematous stroma. On careful high-power scrutiny these nodules show cords and sheets of dark blue Sertoli cells and eosinophilic Leydig cells. Mitotic rate is around 5/10hpf.

- Poorly differentiated (sarcomatoid) - dominant sarcomatoid stroma resembling primitive gonadal stroma. It lacks the lobular arrangement of intermediate differentiated tumours. Mitosis is high, around 20/10 hpf. A thorough search for cords of Sertoli cells and Leydig cells is essential for diagnosis.

- With heterologous elements - mucinous epithelium of GIT, liver, endocrine cells, carcinoid, skeletal muscle, cartilage, rhabdomyosarcoma etc.

- Retiform - $90 \%$ of the tumour is comprised of ramifying network of slit-like spaces

- Pure Sertoli cell tumour - similar to well differentiated tumour but lacking the Leydig cells and stromal elements

Treatment options include surgery with or without adjuvant chemo and radiotherapy. In young women, where preservation of fertility is desired, unilateral salpingo-oophorectomy is done, if the tumour is stage IA. More aggressive surgical therapy with chemo/radiotherapy is indicated for advanced stage tumours and tumours with poor prognostic features. ${ }^{3}$

Patient had tumour confined to the ovary and was treated surgically with total abdominal hysterectomy with bilateral salpingo-oophorectomy. Prognosis of SLCTs is generally good due to the fact that $80 \%$ of them are in stage IA of FIGO, fully encapsulated, and moderately differentiated and depends on the stage and degree of differentiation of tumours. Poor differentiation, presence of heterologous elements, high mitotic counts and rupture of tumour are associated with increased risk of metastasis. Adjuvant chemotherapy is recommended for patients with advanced stage, intermediate and poor differentiation, retiform pattern, and presence of heterologous elements. ${ }^{4}$

\section{CONCLUSION}

To conclude, SLCTs are rare ovarian tumours belonging to the group of sex cord stromal tumours. Absence of endocrine manifestations, presentation in postmenopausal age group (Less than $10 \%$ of patients are reportedly older than age 50), and this big size of the tumor, were the unusual features observed in this case.

\section{Funding: No funding sources \\ Conflict of interest: None declared \\ Ethical approval: Not required}

\section{REFERENCES}

1. Robboy SJ, Mutter GL, Prat J, Bentley RC, Russell P, Anderson MC. Robboy's Pathology of the Female Reproductive Tract. $2^{\text {nd }}$ ed. Edinburgh: Churchill Livingstone; 2008.

2. Kurman RJ. Blaustein's Pathology of the Female Genital Tract. 5th ed. New York: Springer; 2002.

3. Young RH, Scully RE. Ovarian Sertoli-Leydig cell tumors. A clinicopathological analysis of 207 cases. Am J Surg Pathol. 1985;9:543-69.

4. Gui T, Cao D, Shen K, Yang J, Zhang Y, Yu Q, et al. A clinicopathological analysis of 40 cases of ovarian Sertoli-Leydig cell tumors. Gynecol Oncol. 2012;127:384-9.

Cite this article as: Raghav M, Anand AR. Huge Sertoli-Leydig cell tumor: a rare case report. Int J Reprod Contracept Obstet Gynecol 2020;9:432-6. 